\title{
Research and Utilization on Waste Heat of
}

\section{Dyeing and Printing Factory}

\author{
Shensheng Zhou \\ Institute of Chemical Machinery and Safety \\ Engineering \\ South China University of Technology \\ Guangzhou, China \\ e-mail:527892077@qq.com \\ Nan Jiang \\ Institute of Chemical Machinery and Safety \\ Engineering \\ South China University of Technology \\ Guangzhou, China \\ e-mail:inscut@126.com
}

\author{
Bo Deng \\ FS branch institution of GDSEI \\ Gang Dong Special Equipment Inspection \\ Foshan, China \\ e-mail:14935796@qq.com
}

\begin{abstract}
In order to recycle the waste heat of the dyeing and printing factory, analysis about dyeing and printing waste heat and its current running system of the factory were obtained in this paper. Analysis indicated that most of the waste heat was unemployed. The recycling order of all kinds of waste heat available confirmed after the calculation of them by using thermodynamic method. A waste heat utilization scheme with two recycling stations was designed to solve the problem of heat wasting. Practice shows that the scheme is effective and economical. It brings the factory with $80 \%$ recovery rate and nearly 6 million Yuan cost saving.
\end{abstract}

Keywords: waste heat utilization; dyeing and printing industry; Boiler; waste heat calculation; economic benefit

\section{INTRODUCTION}

The 12th five-year plan for energy conservation and emissions reduction is one of the important measures to carry out the sustainable development strategy of China. The task of energy conservation and emissions reduction was also given by the plan that country's ten thousand Yuan GDP energy consumption must drop to 0.869 tons of standard coal by the year 2015 which drops 16 percentage compared with 2010 and 32 percentage compared with the year of $2005^{[1]}$. Dyeing and printing industry is energy intensive and with high water consumption and high pollution in the world ${ }^{[2]}$. With the situation of energy tension, water resources shortage and environmental pollution, it has become more and more important to pay special attention to the enterprise's energy conservation and emissions reduction, clean production and resource reuse. The method of waste heat recovery with less investment and quick effect is widely used by dyeing and printing factories ${ }^{[3]}$.

\section{Hai Li}

Foshan self-reliance boiler engineering co., LTD, Foshan, Country e-mail: 952551169@qq.com

II. WASTE HEAT RESOURCES OF DYEING AND PRINTING INDUSTORY AND ITS PRESENT RECYCLING SITUATION AND TECHNOLOGY

\section{A. Waste heat resources of dyeing and printing industry}

\section{1) Waste heat of liquid}

Waste water with high temperature comes from the production process of dyeing and printing factory includes the condensate water, cooling water and dyeing and printing waste water. The energy of the water is valuable. The temperature of the condensate water is nearly $100^{\circ} \mathrm{C}$ and the dyeing and printing waste water is nearly $60^{\circ} \mathrm{C}{ }^{[4]}$. Most of the hot water is directly discharged without recycling use. This causes the rise of the temperature of the sewage pool on the one hand and serious pollution and energy waste on the other hand.

\section{2) Waste heat of gas}

Waste gas of the boiler and setting machine are also high of heat. Saturated steam is the main energy resource of the dyeing and printing industry. The temperature of the waste smoke of the boiler is more than $220^{\circ} \mathrm{C}$ and the smoke of the setting machine is $120^{\circ} \mathrm{C}{ }^{[5]}{ }^{[6]}$. The emissions of these smokes bring serious air pollution and energy wasting to the environment.

\section{B. The present recycling situation of waste heat resources of dyeing and printing industry.}

China is a country with many big dyeing and printing factories. Massive discharge of waste water and gas are the result of the production of these factories. According to incomplete statistics that the water consumption of the dyeing and printing industry is 9.548 billion tons .Most of the water is directly discharged by using the saturated steam as the main energy resource. But, the energy utilization rate is only about $35 \%{ }^{[7]}$. Sixty-five percentage of the energy is wasted in different ways without reasonable use.The recovery rate of waste is really low in this field. The quantity of waste water and gas discharged 
by those factories is so big that the recycle of them will brings large economic benefit.

\section{Technologies of Waste heat recycle}

Along with the rising coal prices, the price of saturated steam stays high. The rising energy costs compress the profit margins of the enterprise further.The strategy of energy conservation and emissions reduction leaves the enterprise's development awkward by facing severe challenges. Many enterprise start digging their own potential to reverse the situation. The method of waste heat recovery is more and more popular with dyeing and printing factories.

Even the technology of waste heat-recycle starts late. But it has made big progress by its fast development. Many kinds of technologies have been applied into practice. The technologies by using waste are: dyeing and printing waste water heat recovery by using heat pump technology, waste heat conversion by using plate heat exchanger, waste water heat recovery by using continuous set, multistage series heat exchanger and so on ${ }^{[8]}$. Waste gas of the boiler and setting machine are the main part of the waste gas-heat. Different technologies are used according to different situations and heat exchanger such as rotary heat exchanger, heat medium heat exchanger, heat pipe heat exchanger and economizer are the most commonly used machine ${ }^{[9]}$. Cooling - high voltage static electricity technology and traditional water spray technology are specially used to recycle the waste heat of the smoke of the setting machine ${ }^{[6]}$.

\section{ENGINEERING BACKGROUND}

Junyou dyeing and printing factory is the enterprise which is specially engaged in textile fabric dyeing and printing industry. Waste water with high temperature comes from the production process of dyeing and printing is discharged directly. This causes serious pollution and energy waste at the same time. There is a circulating fluidized bed boiler of $25 \mathrm{t} / \mathrm{h}$ and a set of smoke condensation type generating units of $1500 \mathrm{kw}$ in this factory. The saturated steam produced by the boiler and the electricity generated by the generator are provided to the 10 enterprises including the factory itself. The survey found that the continuous sewage of the boiler and the cooling oil of the the steam turbine also contains abundant heat. According to this sisuation, a scheme is need to be made by using new type of multistage tandem heat exchanger to recycle those kinds of waste heat in this factory.

\section{THE CALCULATION OF WASTE HEAT}

\section{A. The hot medium}

According to the test, the temperature and flow rate of all kinds of waste heat available are showed in the table blow.

The calculation is based on the formula in $\mathrm{GB} / \mathrm{T}$ $1208-2000^{[10]}$ :

$$
Q_{y}=\sum_{i}^{n} m_{i}\left[Q_{d i}{ }^{y}+\left(h_{1 i}-h_{2 i}\right)\right] \tau_{i}
$$

TABLE I. THE TEMPERATURE AND FLOW RATE OF ALL KINDS OF

\begin{tabular}{|c|c|c|c|}
\hline NO. & Medium & Temperature & Flow \\
\hline 1 & Cooling water & $55-65$ & $25 \mathrm{t} / \mathrm{h}$ \\
\hline 2 & Condensate water & $90-100$ & $6 \mathrm{t} / \mathrm{h}$ \\
\hline 3 & Sewage of the boiler & 200 & $1 \mathrm{t} / \mathrm{h}$ \\
\hline 4 & $\begin{array}{c}\text { Cooling oil of the the } \\
\text { steam turbine }\end{array}$ & 45 & $20 \mathrm{t} / \mathrm{h}$ \\
\hline
\end{tabular}

Explanation:

$Q_{y}$----The amount of the waste of the year, $\mathrm{KJ} / \mathrm{a}$; $\mathrm{m}^{3} / \mathrm{h}$;

$m_{i}$----The flow rate of the NO.I medium, $\mathrm{kg} / \mathrm{h}$ or

$Q_{\text {diy }}{ }^{\text {----The combustion value of the NO.I medium }}$ $\mathrm{KJ} / \mathrm{kg}$ or $\mathrm{KJ} / \mathrm{m} 3$;

$h_{1 i}$----The enthalpy value of the NO.I medium when it comes out, $\mathrm{KJ} / \mathrm{kg}$ or $\mathrm{KJ} / \mathrm{m}^{3}$;

$h_{2 i}$----The enthalpy value of the NO.I medium under floor temperature, $\mathrm{KJ} / \mathrm{kg}$ or $\mathrm{KJ} / \mathrm{m}^{3}$;

$\tau_{\mathrm{i}}$----The running hours of the machine with the NO.I medium pre year.

In the process of calculation, the enthalpy value of the condensate water, cooling water and dyeing and printing wastewater are taken corresponding to their temperature. The floor temperature is $25^{\circ} \mathrm{C}$ related to the environment. The value of the heat of the Cooling oil of the the steam turbine is based on the following formula:

$$
Q=c \cdot \Delta T \cdot q
$$

The Specific heat capacity is $0.667 \mathrm{KJ} / \mathrm{kg}{ }^{\circ} \mathrm{C}$. Make the running hour of the machine with hot medium 6000 pre year and the results of the calculation are showed in the table blow.

TABLE II. THE VALUE OF THE WASTE HEAT

\begin{tabular}{|c|c|c|c|c|}
\hline $\begin{array}{c}\text { Waste } \\
\text { heat }\end{array}$ & $\begin{array}{c}\text { Cooling } \\
\text { water }\end{array}$ & $\begin{array}{c}\text { Condensate } \\
\text { water }\end{array}$ & $\begin{array}{c}\text { Sewage of } \\
\text { the boiler }\end{array}$ & $\begin{array}{c}\text { Cooling oil } \\
\text { of the the } \\
\text { steam } \\
\text { turbine }\end{array}$ \\
\hline $\begin{array}{c}\text { Value } \\
(\mathbf{K J})\end{array}$ & $2.1943 \times 10^{10}$ & $1.055 \times 10^{10}$ & $6.323 \times 10^{7}$ & $2.668 \times 10^{5}$ \\
\hline
\end{tabular}

The total value of the waste heat reaches to $3.255645 \times 10^{10} \mathrm{KJ}$. It's a huge amount of energy worth to be reused.

\section{B. The cold medium}

The recycle of the waste heat Depends on the two sides: the hot medium and the cold medium. The value of the heat the cold medium needs determines the recovery rate. The temperature and flow rate of the cold medium available are showed in the table blow. 
TABLE III. THE TEMPERATURE AND FLOW RATE OF THE AVAILABLE COLD MEDIUM

\begin{tabular}{|c|c|c|c|}
\hline NO. & Medium & $\begin{array}{c}\text { Temperature } \\
\left({ }^{\circ} \mathrm{C}\right)\end{array}$ & Rate of flow \\
\hline 1 & $\begin{array}{c}\text { original } \\
\text { water of the } \\
\text { boiler }\end{array}$ & 25 & $17 \mathrm{t} / \mathrm{h}$ \\
\hline 2 & $\begin{array}{c}\text { Combustion } \\
\text { air of the } \\
\text { heat } \\
\text { conduction } \\
\text { oil furnace }\end{array}$ & 125 & $4800 \mathrm{Nm} 3 / \mathrm{h}$ \\
\hline 3 & $\begin{array}{c}\text { Combustion } \\
\text { air of the } \\
\text { boiler }\end{array}$ & 150 & $20000 \mathrm{Nm} 3 /$ \\
$\mathrm{h}$
\end{tabular}

All the steam the factory needs comes from the boiler. The coal burns in the boiler turning the water into stream. So the temperature of the original water determines the consumption of coal of the boiler ${ }^{[11]}$. This makes it clear that the original water of the boiler can be used to absorb the waste heat of the heat medium. The largest value of the heat the water can absorb reaches to $3.204 \times 1010 \mathrm{KJ}$ according to the formula.

\section{THE PROJECT DESIGN OF THE WASTE HEAT'S RECYCLING}

\section{A. The design of the heat station in the workshop}

The recycling of the condensate water is the most important part of the project. It recycles not only the heat but also the water itself. Considering the strict requirements of the pressure of condensation water of textile industry and the possibility of hydrophobic contaminated, the system is designed under the atmospheric pressure: the Condensate drain was collected and set into a tube type heat exchanger where it exchanges the heat with boiler's water. The flash steam is eliminated and the latent heat of vaporization is also released in the exchange. Then the collected water is transported to deoxidizing tank

The heat station was designed based on the analysis above. The station includes Pipeline, filters, flash tank, heat exchanger, and heat pump and control system. The process of the heat station is showed in the Fig .2. The flash tank in Fig .1 is specially designed for the station which can filter the impurities and protect the plate heat exchanger at the same time.

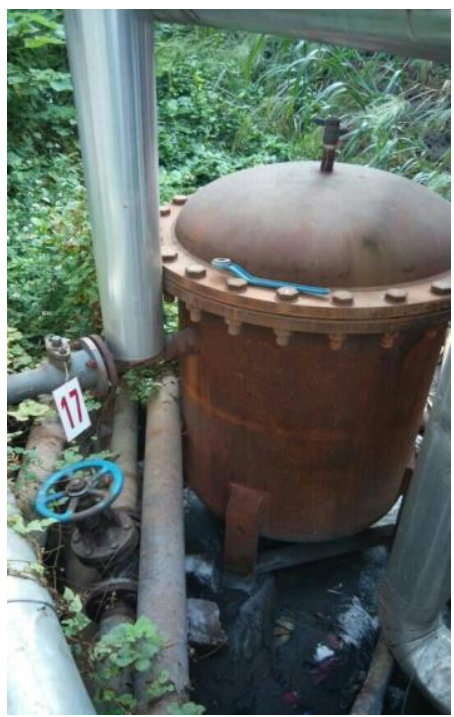

Figure 1. Flash tank

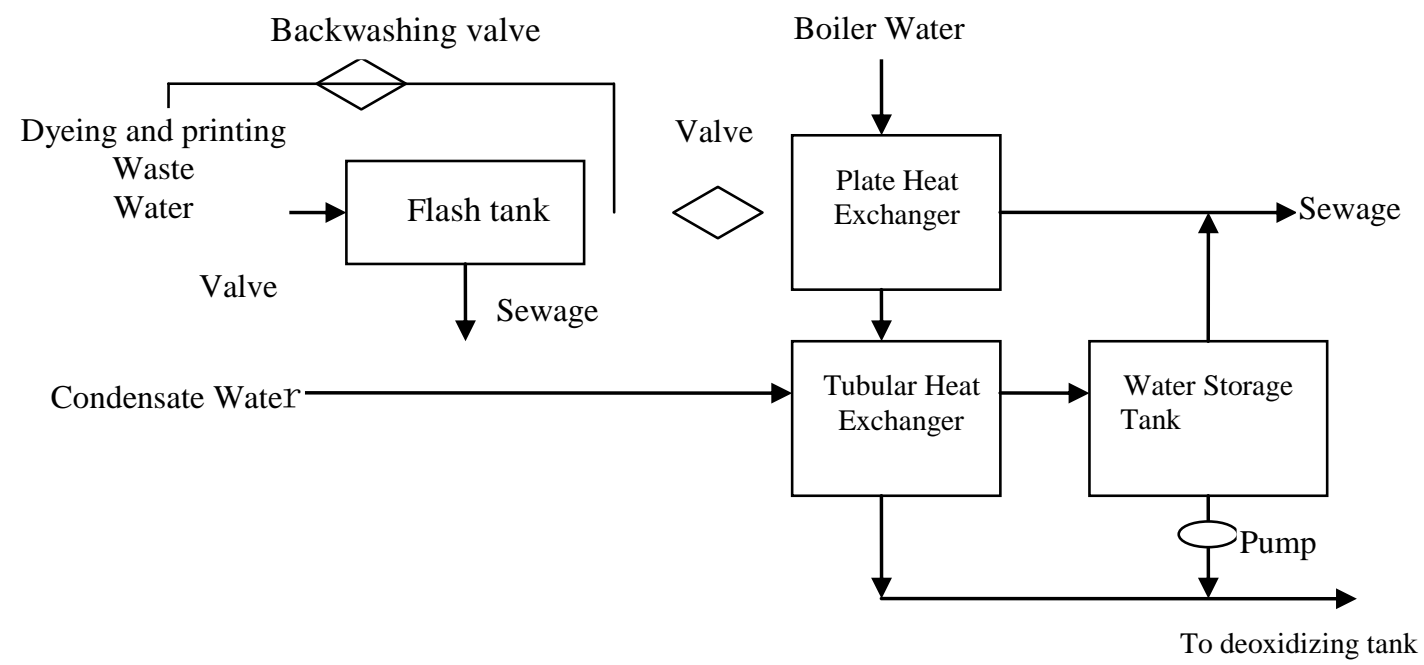

Figure 2. The flow chart of the heat station 


\section{B. The recycle of the heat of other mediums}

Another two heat exchanger were used to recycle the heat of continuous sewage of the boiler and the cooling oil of the the steam turbine (heat exchanger 2 and heat exchanger 3). Both two of these heat exchangers are tubular heat exchanger and they are showed in the picture blow. The heat exchanger 3 is essential because it can protecte the steam turbine from overheating even though the value of the heat of cooling oil of the the steam turbine is less than other medium.

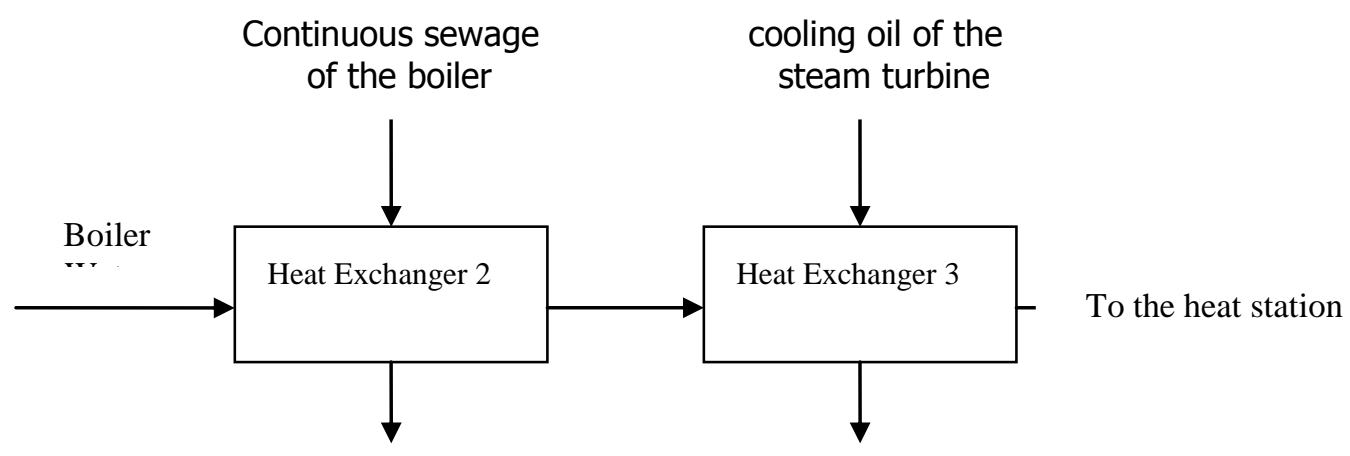

Figure 3. The recycle of the heat of other medium

\section{C. recovery rate}

The whole system is running well after the project's implementation. There is also no bad influence to the boiler and all heat exchangers are in the scope of stability as predicted. The boiler water goes through the two heat stations and its temperature rises from $25^{\circ} \mathrm{C}$ to $85{ }^{\circ} \mathrm{C}$ after that. The real value of the heat recycled is $2.561 \times 10^{10} \mathrm{KJ}$ and the recovery rate reaches to $80 \%$.

\section{Economic benefit evaluation}

The consumption of coal declined with rising of the temperature of the boiler water. It drops from $6955 \mathrm{~kg} / \mathrm{h}$ to $6775 \mathrm{~kg} / \mathrm{h}$ because of the whole plan of heat recycling. The whole project saved 1080 tons of coal for the factory if it runs 6000 hours per year. 30000 tons of flesh water was saved at the same. The whole plan created a economic benefit as much as 5.928 million Yuan according to the coal price and water price at present.

\section{CONCLUSION}

The scheme of waste heat recycling is effective and economical. It brings the factory with $80 \%$ recovery rate and nearly 6 million Yuan cost saving. It meets the request of the sustainable development strategy of China. According to the investment situation of the scheme, system which runs for half a year will recover the investment costs. This provides a good reference to other dyeing and printing factory who wants to do waste heat recycling.

\section{REFERENCE}

[1] MIIT. The 12th five-year plan for energy conservation and emissions reduction $[\mathrm{J}]$. Supervision Test and Cost of Construction, 2012,(5) : 3-16.

[2] Liu Yunmin. Present status of exhaust heat recovery of dyeing and printing and printing industry in Changzhou district [J].Dyeing and printing and Finishing, 2010,(1) : 50-57.

[3] Chen Liqiu. Energy saving and emission reduction technology in dyeing and printing and finishing industry $[\mathrm{M}]$. Beijing: Chemical Industry Press, 2009.

[4] Gong Haihua. Comprehensive Utilization of Dyeing and printing and Printing Waste Heat. [J]. China Resources Comprehensive Utilization, 2011, (4) : 35-37.

[5] Jia Hongbing,Wang Weimin. Comprehensive Utilization of residual heat and waste gas. [J]. Dyeing and printing and Finishing, 2008, (14) : 41-43.

[6] Gu Zhenyu, Shao Zhenhua, Chen Dequan. Cooling-static high integration technology application of the exhaust heat of setting machine.[J]. Environmental pollution and control, 2008, 30 (9) : 85-87.

[7] Lin Lin. Present situation of energy-saving and pollution-reduction in dyeing and printing and printing industry[ $[\mathrm{J}]$. .Dyeing and printing and Finishing, 2008, (2) : 40-43.

[8] Zhu Renxiong. Energy efficiency and ecology of dyeing and printing machines[J]. Dyeing and printing and Finishing,2011,(5) : 47-49.

[9] Tong Qingju, Wang Xuemin. Boiler flue gas waste heat recycling technology $[\mathrm{J}]$. Science and Technology Innovation Herald,2009,(18):71-73

[10] GB/T 1028-2000, Terms, classification ,grade of waste heat in industry and calculating method of quantity of waste heat resources.[S]

[11] Wang Shanwu. Energy Conservation and Emission Reduction, Strategic

Development for Industrial Boiler Industry $[\mathrm{J}]$. Industrial Boiler,2011,125(1):1-9. 